\title{
Measuring the Level of Satisfaction with Respect to the Quality of Services Provided by the Local Tourist Destination in Mashhad, Iran
}

https://doi.org/10.21272/sec.3(1).64-71.2019

\section{Rostam Saberifar}

Department of Geography, College of Economic and Social Science, Payam-e- Noor University, Tehran, Iran

Uday Chatterjee

Dr., Assistant Professor, Department of Geography, Bhatter College, Dantan, Vidyasagar University, West Bengal, India

\section{Gouri Sankar Bhunia}

GIS Division, Aarvee Associate Architect Engineers and Consultant Pvt Ltd, Hyderabad, India

\begin{abstract}
This paper summarizes the arguments and counterarguments within the scientific discussion on the issue of satisfaction level of tourists in Mashhad through an analytical method. The main purpose of the research is to assess the level of socio-cultural and environmental conditions and the tourist services facilities of Mashhad. Systematization literary sources and approaches for solving the problem of tourism development indicates that the tourism economy in Mashhad has special stability in terms of economic factors. Field studies were conducted during the period between April and June 2014 in the form of a questionnaire. For investigation of the topic, a total of 335 internal tourists in Mashhad were selected. For analyzing data and explaining the subject of the study, Mann-Whitney, Kruskal-Wallis, Spearman, Chi-Square, and one-sample t-tests were used to understand the relationship between tourist experience and socio-cultural as well as environmental conditions and infrastructure facilities respectively. The paper presents the results of an empirical analysis indicated that the tourists were largely satisfied with the socio-cultural and environmental conditions as well as existing infrastructure facilities. Accordingly, no significant $(P$-value $<0.13)$ difference between men and women tourist population were shown. Meanwhile, the tourists with different levels of education had the same views on the consent for all parameters (Kruskal-Wallis test -4.035 P-value $<0.13$ ) of the tourists. The research empirically confirms and theoretically proves that no significant correlation between the length of residence and the level of satisfaction with tourism conditions ( $\mathrm{r}=0 / 113, P$-value $<0.038)$, host society interactions (x2 $=106 / 107, P$-value $<0.000)$ and significant differences between attitudes of men and women (MannWhitney $=3753 / 5, P$-value $<0.000$ ). Also, tourists with different educational levels had different views considering how to deal with the host community (Kruskal-Wallis test $10.754 ; P$-value $<0.005$ ). The results of the research can be useful for sustainable development of the tourism industry and tourism management.
\end{abstract}

Keywords: tourism industry, suitability analysis, Mashhad.

JEL Classification: Z30, Z32, Z39.

Cite as: Saberifar, R., Chatterjee, U., Bhunia, G. S. (2019). Measuring the Level of Satisfaction with Respect to the Quality of Services Provided by the Local Tourist Destination in Mashhad, Iran. SocioEconomic Challenges, 1(3), 64-71. https://doi.org/10.21272/sec.3(1).64-71.2019.

(C) The Authors, 2019. This article is published with open access at Sumy State University.

\section{Introduction}

Sustainable tourism development shows a shift from the traditional approach of neoclassical economics in the field of tourism development to a more holistic approach, which not only highlights the market needs but also the needs of society and the natural environment (Saberifar et al., 2015). Sustainable tourism development is a process that improves the quality of the host's life, supplies the demand of visitors, and protects the natural 
and human environment (Ghadami, 2011: 60). Accordingly, tourist areas require efficient management and development efforts in the direction of sustainability (Saifuddin and Shorcha, 2011). There are several conceptual frameworks regarding the implementation of sustainable development of tourism, where most discussions are dedicated to the capacity of reception (Rahnamaei et al., 2008: 19). Mashhad has an advantage renowned lighting competition. Evaluating the capacity of reception is one of the main techniques for planning and tourism management, whose purpose is to determine the very favourable limits of development in order to provide efficient use of tourism resources. The capacity of reception indicates that tourism destinations have some limitations for a particular area to tolerate without provoking any irreparable risk (Bonilla \& Bonilla, 2008). Protection and improvement of tourism environment can be done using the income of tourism. In fact, the funds required for preserving historical monuments and generally the tourism environment are provided by tourism (Soltani and Shahnoushy, 2012).

\section{Literature review}

Satisfaction is a feeling that people experience when they achieve to their dreams. Satisfaction needs a satisfying factor such as reward or a situation that leads to satisfaction. From a sociological perspective, satisfaction enhances the legitimacy and stability of the administrative systems. From the perspective of management, customer satisfaction is among the basic principles of quality management and it is also an important criterion for the model of organizational excellence (Firoozabadi and Imani, 2012: 63).

One of the major issues facing the institutions which receive tourists is to identify the level of satisfaction considering provided services and the effective factors. The importance of satisfaction is not limited to travel in one sphere of life. Travel satisfaction leads to life satisfaction, because the leisure time, along with health, family life, and work is one of the four main areas of life (Noghani et al., 2012: 117). According to the "World Tourism Organization", "customer satisfaction" is defined as "a psychological concept that includes the pleasure arising from the acquisition of a product or service that one expects" (Chi, 2005: 48). Most countries will be successful in attracting tourists because of providing the necessary infrastructure according to their cultural and geographical features; note that providing required facilities is the first step in attracting and keeping tourists (Ebrahimpur and Roshandel, 2011: 4). Generally satisfaction is a multidimensional concept and becomes more complex especially when the destination is more considered instead of service provider. For the destination, satisfaction is evaluated based on many aspects of the travel experience including services and facilities (Truong \& Foster, 2006: 843).

Attention to the measurement of customer satisfaction in tourism is due to the need to competitive positioning in the global market. The main outcome of this measurement is providing information on how a destination already corresponded to the needs of tourists (Wong \& Law, 2003: 403).

There have been several studies for evaluating the level of tourists' satisfaction, some of which will be mentioned here:

Nourollahi (1383) believes that one of the satisfaction strategies in travel, is the tourism-oriented programming. In general, there are three major stages in the planning of tourism:

1. Planning for the arrival of tourists

2. Planning for the period that the tourist is together with us.

3. Planning for the end of the travel (Divine Light, 2004: 109).

Regarding satisfaction of tourists from other tourist destinations, several studies have been done, some of which are mentioned below:

Rahnamaei et al. (2012) examined the amount of tourist satisfaction according to the quality of hotel services in Mashhad. Based on the results, the first factor in satisfaction was suitable access to convenient transportation from the hotel to the attractions. The second factor was the quality of hotel foods. According to the assumption test, there was a significant relationship between satisfaction from the quality of service and field variables. 
Anabstany et al. (2012) examined the development of rural tourism in Arjan plain of Fars from the perspective of tourists and villagers. They found that the development of tourism had positive changes in the economic, social, physical, and ecological aspects for the villages in the area.

Noghani et al. (2012) examined the effective factors in satisfaction of foundation martyr families when they visited the Mashhad. They found that the variables affecting satisfaction of tourists in the host community, were not only the facilities provided by the host community, but also a part of satisfaction was related to the idea about host community and the expectations formed on the basis of host community.

Gemini and Jamshidi (2012) identified and prioritized the factors affecting the level of tourist satisfaction in market of border of Javanrood city. The results showed that economic factors were the most important factors in tourist satisfaction from the markets.

Bayat et al. (2013) investigated the effective factors and their impact on the behavior of internal tourists in the brand image of Qazvin. They found that the overall destination picture in the tourist mind had an important role in shaping the decision to visit again or recommending to others.

As can be seen, there is no comprehensive research about the measurement of satisfaction of internal tourists in Mashhad (from various aspects of social, environmental situation and services). Hence, this study deals with this subject, because Mashhad is not only the important tourism city of Iran, but it is also concerned in the Islamic world from the perspective of cultural and religious tourism. Mashhad (Geographic pilgrims) is one of the holy cities of the world, whose nature, spatial formation, and socio-economic life is entirely affected by religious, cultural, and tourism factors (Soltani and Shahnoushy, 2012: 8). Thus investigation of internal tourist satisfaction in this city will help policy makers in creating and planning for the future expansion of existing facilities.

\section{Study area}

The study area was the city of Mashhad which is the second metropolitan and also the largest religious city of Iran with a history of 1200 years due to the presence of the shrine of 8th Imam of Shia. The city covers an area of over $300 \mathrm{~km}^{2}$ and had a population of over 2.77 million in 2011 (Rahnama et al., 2012: 71). Mashhad is expanded over the Kashf-Rud river basin, on the plain of Mashhad and between two mountains of HezarMasjed and Binalud. This locality is an indicative sign of it being a mountainous city with a maximum of 1150-meters and a minimum of 950-meters elevation from sea level. The weather in Mashhad is moderate and variable, and winds are most in direction of the south-east to north-west. The maximum temperature in the summer is 43 degrees above zero, and the lowest temperature in winter is 23 degrees below zero (Statistics of Mashhad, 2018). Because of the shrine of Imam Reza, Mashhad is the spiritual capital of Iran and the international excellent pilgrimage, to which more than 20 million internal and foreign pilgrims and tourists travel every year (Saghayee et al, 2011: 74). The best of Islamic art and architecture and be seen in this place, containing the unique and significant monuments in which context Islamic arts and faith are embedded.

\section{Methods}

An analytical method is used in the study, while for collecting statistical information, library and statistical studies, as well as surveys have been used. Literature and statistical resources were used for theoretical research. In order to determine the level of satisfaction considering the quality of services provided in Mashhad, some measures were selected and field studies were done in preparation, drafting, and completion of the questionnaire. Questionnaires were filled in April - June 2014. Closed type multiple choice questions were chosen in the field survey. Data on sex, education, length of stay, place of stay, the purpose of visit, and overnight stay along with characteristics of the tourists were collected through face to face interviews. Sequential questions were arranged in the form of Likert with a score of 1 (very low) to 5 (very much) and evaluated the tourist attitudes. Cochran method was used to select the sample size and a total of 335 internal population of Mashhad was considered. In order to analyze data and explain the subject of study, Mann-Whitney, KruskalWallis, Spearman, Chi-Square, and one-sample t-tests were used to understand the relationship between tourist experience and socio-cultural as well as environmental conditions and infrastructure facilities respectively. All the statistical analyses have been performed at $95 \%$ confidence interval. Statistical analysis has been carried out in Microsoft Excel. 


\section{Results}

\section{The demographic profile of respondents}

Out of the total tourist respondents, $12 \%$ were male and $88 \%$ were female. Results also showed that $68.4 \%$ of total respondents were between 25 and 45 years, $28.1 \%$ were between $15-25$ years, and the remaining $3.3 \%$ were between 10-15 years old. Based on the educational status, the total tourist population was categorized into three groups of tourist respondents and the results showed that $83 \%$ of respondents had graduate and higher degrees, $16.7 \%$ were higher secondary level, and $0.3 \%$ were secondary level or below. Tourists arriving in Mashhad, often visit this city more than once, so that about $90 \%$ of them visit Mashhad for the second time or more. $68 \%$ of the tourists resided in Mashhad between 1-3 days, $29 \%$ between 4-7 day and only 3.3\% of them resided more than 8 days in Mashhad. 22.4\% of respondents stayed in hotels, $43 \%$ in hotel-apartments, $20 \%$ in inns, $6.6 \%$ in motels, and $1.8 \%$ in the homes of friends and acquaintances. In the scenario of the trip's purpose, half of the respondents claimed to have fun and pilgrimage, $36.7 \%$ pilgrimage only, $10.4 \%$ trade and commercial activities, and only $3.3 \%$ leisure in the city (Table 1).

Table 1. Demographic characteristics of internal tourists in the city of Mashhad

\begin{tabular}{|c|c|c|c|}
\hline Variable & Classification & Number & Per cent \\
\hline \multirow{2}{*}{ Sex } & Male & 41 & 12 \\
\hline & Female & 294 & 88 \\
\hline \multirow{3}{*}{ Education } & Primary school & 1 & 0.3 \\
\hline & High school & 56 & 16.7 \\
\hline & College & 278 & 83 \\
\hline \multirow{3}{*}{ Length of stay } & $1-4$ & 227 & 67.8 \\
\hline & $4-7$ & 97 & 29 \\
\hline & +8 & 11 & 3.3 \\
\hline \multirow{5}{*}{ Place of stay } & Hotel & 75 & 22.4 \\
\hline & Hotel-apartment & 144 & 43 \\
\hline & Inn & 67 & 20 \\
\hline & Motel & 22 & 6.6 \\
\hline & Homes of friends and acquaintances & 27 & 8.1 \\
\hline \multirow{4}{*}{ Propose } & Leisure and fun & 11 & 3.3 \\
\hline & Pilgrimage & 123 & 36.7 \\
\hline & Fun and pilgrimage & 166 & 46.9 \\
\hline & commercial activities & 35 & 10.4 \\
\hline \multirow{3}{*}{ Cause of overnight stay } & Suitability of place & 144 & 43 \\
\hline & The price suitability of the place & 157 & 46.9 \\
\hline & Catering facilities & 34 & 10.1 \\
\hline
\end{tabular}

Source: primary data collected through the questioner survey during the period between April and June 2014 .

\section{Socio-cultural and environmental conditions, facilities, and services in Mashhad}

Tourism in the city of Mashhad has different impacts on satisfaction of internal tourists in various aspects of environmental and socio-cultural facilities and services (Table 2). Generally, the majority of tourists travelling to Mashhad are satisfied $(\bar{x}=4.4)$ and the facilities and services for tourists and tourism development are appropriate from their point of view $(\bar{x}=3.4)$. From the view of tourists, the quality of catering units is in good health $(\bar{x}=3.4)$ and safety conditions are provided in this city $(\bar{x}=3.4)$. Tourists believe that tourism has an important role in increasing congestion $(\bar{x}=4.1)$; they said that the social space of Mashhad is partly appropriate for leisure $(\bar{x}=3.3)$. Tourists said that the performance of urban management is good. Those who have visited the city for the first time believed that the overall current situation was somewhat accommodating to their image $(\bar{x}=3.2)$. Many tourists like to have a house in the city, if possible $(\bar{x}=3.3)$. Life and culture of the city has a little attraction for internal tourists $(\bar{x}=2.9)$. Moreover, health and cleanliness $(\bar{x}=3.2)$ and environmental situation $\mathrm{n}(\bar{x}=3.2)$ are suitable for the development of tourism indthe ustry. 
Table 2. Comments of tourists in relation to the tourism conditions in the city of Mashhad

\begin{tabular}{|c|c|c|c|c|c|c|}
\hline Items of research & $\begin{array}{l}\text { Very } \\
\text { low }\end{array}$ & Low & $\begin{array}{l}\text { Some } \\
\text { extent }\end{array}$ & High & $\begin{array}{l}\text { Very } \\
\text { high }\end{array}$ & Mean \\
\hline Are you satisfied with the travel to the city of Mashhad? & 4.2 & - & 13.8 & 14 & 68 & 4.4 \\
\hline $\begin{array}{l}\text { Are the facilities and services of the city for tourists and tourism devel- } \\
\text { opment appropriate? }\end{array}$ & 6.6 & - & 52.5 & 26.3 & 14.3 & 3.4 \\
\hline Is the quality of catering units appropriate? & 6.6 & 8.4 & 35.2 & 26.3 & 21.8 & 3.4 \\
\hline How is the safety of tourists in the city? & 3.3 & 4.2 & 53.1 & 26.3 & 13.1 & 3.4 \\
\hline What is the role of tourism in increasing congestion? & - & 3.3 & 18.8 & 33.7 & 44.2 & 4.1 \\
\hline $\begin{array}{l}\text { How is the quality of management in line with the demands of tourists in } \\
\text { the city of Mashhad? }\end{array}$ & - & 20.6 & 35.5 & 27.8 & 16.1 & 3.3 \\
\hline $\begin{array}{l}\text { If you're travelling here for the first time, is the overall current situation } \\
\text { somewhat accommodating to your image? }\end{array}$ & - & 15.8 & 49 & 30.7 & 4.5 & 3.2 \\
\hline $\begin{array}{l}\text { In your opinion, how is the social space of the city to spend your leisure } \\
\text { time? }\end{array}$ & 4.2 & 12.5 & 38.2 & 33.7 & 11.3 & 3.3 \\
\hline Are you willing to have a home in this city? & 23 & 4.2 & 19.4 & 26.3 & 27.2 & 3.3 \\
\hline Is life and culture of the people attracted to you? & 16.4 & 16.1 & 27.5 & 33.1 & 6.9 & 2.9 \\
\hline In your opinion, how is the state of health and cleanliness in this city? & 9 & 11 & 44.2 & 19.4 & 16.4 & 3.2 \\
\hline How much did the environmental situation in this city satisfy you? & 13.1 & 4.2 & 36.7 & 31.9 & 14 & 3.2 \\
\hline
\end{tabular}

Source: primary data collected through our questioner survey during the period between April and June 2014.

The result of our analysis also showed that tourists are satisfied with the requirements of the socio-cultural as well as environmental conditions and infrastructure facilities (Chi-Square -226.63; $P$-value $<0.0001$ ). MannWhitney test showed significant differences in satisfaction with the socio-cultural and environmental conditions and infrastructure facilities between men and women (Mann-Whitney - $2479.5 P$-value $<0.0001$ ); this means that the level of satisfaction with the conditions between men and women is different. Alternatively, the Kruskal-Wallis test showed an important relationship with the tourists' activities with different educational levels, who have the same views considering the satisfaction of the socio-cultural and environmental conditions and infrastructure facilities (Kruskal-Wallis test $-4.035 P$-value $<0.13$ ). No statistically significant associations were observed between the length of stay of tourists and their satisfaction level from facilities and services, tourism, social, and cultural conditions $(r=0.113)$. The quality of the host society in Mashhad has a different effect on the internal tourists (Table 3). The positive effects associated with the treatment of the host society, physically (conflict) contacts with the host population were very low $(\bar{x}=1.08)$. Tourists believe that very little face rejection has happened by the citizens of Mashhad, or they feel that they are not strangers $(\bar{x}=$ 2.1). Consequently, the apathy of Mashhad citizens regarding their entry into Mashhad was very little $(\bar{x}=$ 2.2). According to touthe rist's perspective, the amount of welcoming the tourists is largely satisfying for tourists $(\bar{x}=3.1)$, and the amount of Mashhad citizens' activities in attracting tourists is very high $(\bar{x}=3.2)$.

Table 3. Tourists comments in relation to the host city of Mashhad

\begin{tabular}{|c|c|c|c|c|c|c|}
\hline Items of research & $\begin{array}{l}\text { Very } \\
\text { high }\end{array}$ & High & Some & Low & $\begin{array}{l}\text { Very } \\
\text { low }\end{array}$ & Mean \\
\hline Have you had physical contacts (conflict) with Mashhad citizens? & - & - & - & 8.4 & 91.6 & 1.08 \\
\hline $\begin{array}{l}\text { Have you faced with rejection or do you feel like a stranger for Mashhad } \\
\text { citizens? }\end{array}$ & 2.4 & 8.4 & 29.9 & 19.4 & 40 & 2.1 \\
\hline How much is the indifference of Mashhad citizens (the host) with you? & - & 15.8 & 30.7 & 15.8 & 37.7 & 2.2 \\
\hline $\begin{array}{l}\text { In your opinion, what is the level of acceptance and welcoming for tourists } \\
\text { from Mashhad citizens? }\end{array}$ & 11.6 & 22.4 & 40.9 & 19.1 & 6 & 3.1 \\
\hline $\begin{array}{l}\text { In your opinion, how much is the active participation of Mashhad citizens } \\
\text { for attracting tourists? }\end{array}$ & 6.9 & 36.1 & 34 & 10.7 & 12.2 & 3.1 \\
\hline How satisfied are you with the conditions of city residents? & 14.9 & 23.6 & 45.4 & 4.2 & 11.9 & 3.2 \\
\hline
\end{tabular}

Source: primary data collected through our questioner survey during the period between April and June 2014.

Generally, the results show that tourists are satisfied with the style of encountering of Mashhad citizens (ChiSquare test $-106.107 ; P$-value $<0.001)$. Results also showed the significant difference in satisfaction with the 
encountering from host society between men and women (Mann-Whitney $-3753.5 ; P$-value $<0.0001)$. Satisfaction of the encountering from host society and different educational levels indicates that among different educational groups, the satisfaction of the encountering from host society is different (Kruskal-Wallis test 10.754; $P$-value $<0.005)$.

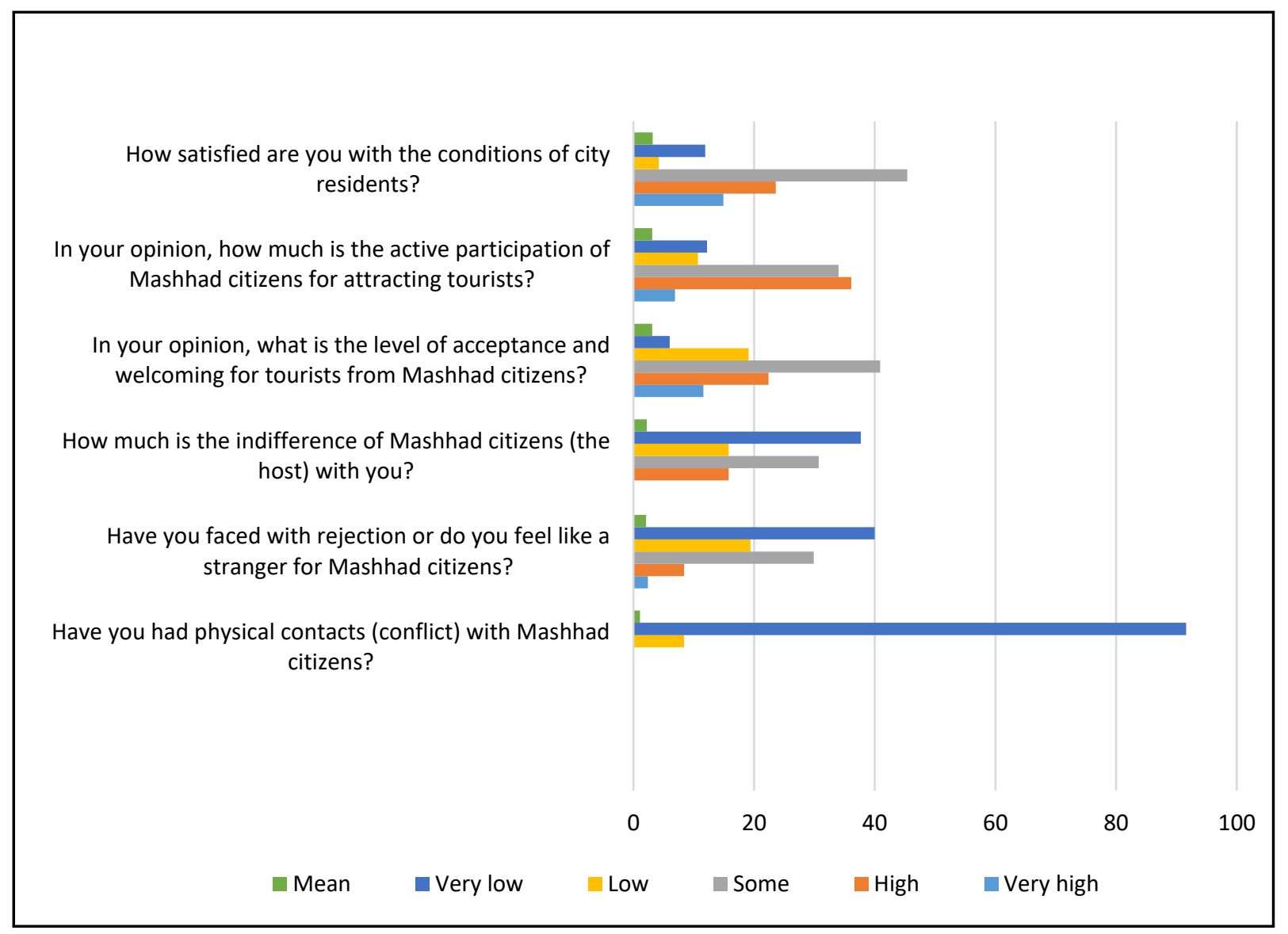

Figure 1. Tourists comments in relation to the host city of Mashhad

Source: primary data collected through our questioner survey during the period between April and June 2014 .

\section{Discussion}

Tourist satisfaction as a key factor in the effectiveness of long-term performance of economical tourism is an important factor (Juandi et al., 2018). Given the importance of evaluating the capacity of tourism in a sustainable development approach, this study aims to evaluate the quality of tourist experience and their satisfaction in Mashhad. In the first aspect, the results indicate that tourists are largely satisfied with all socio-cultural and environmental conditions and infrastructure facilities, and significant differences can be observed between men and women tourists. Meanwhile, tourists with different levels of education, have the same views on the satisfaction context of the tourist conditions. Studies done on the correlation between the level of satisfaction of the conditions and their length of stay indicate that there is no significant correlation between these two variables. In the second aspect, the results show that the internal tourists' satisfaction with the encountering from host society in Mashhad is large, and there are significant differences between the views of women and men. Also, tourists with different levels of education have different views on satisfaction about the encountering from the host society. Based on these results and considering the growing number of internal tourists in the city of Mashhad, efficient planning and management are needed for sustainable development and for further enhancing the positive effects in order to create a positive image for tourists. 
SocioEconomic Challenges, Volume 3, Issue 1, 2019

\section{Conclusions}

The present study is carried out to appraise the fulfilment of tourist towards the socio-cultural and environmental conditions as well as existing infrastructure facilities presented by Mashhad, Iran. Consequently, the interviews have been conducted among the local and foreign tourists. Three types of analysis are employed, namely demographic profile, socio-cultural and environmental conditions and statistical relationships with the tourists. The statistical analysis shows the difference between the tourists apparent means to almost all the socio-cultural and environmental service quality that are assessed by the overall travellers. The outcome of the research suggested that tourists are satisfied with the surrounding environmental conditions and available amenities of Mashhad. However, the controlled development must also be undertaken for improving environmental quality and sustainable tourism development.

\section{References}

1. Ibrahimpour, Habib and Roshandel, Taher (2011). Investigating the factors influencing the tourism based on the expectations and perceptions of tourists and gap analysis (case study: Regional Tourism Sareinin Ardebil). Business Management, 8, 22-31.

2. Imani Khoshkhoo, Mohammad Hossein and Javdaneh, Ali (2011). Satisfaction from the experience of European tourists traveling to Iran. Journal of Tourism and Development, 1(1), 17-30.

3. Baiat, Rouhoallah and Fazli, Safar and Marandi, Mahsa (2012). Factors influencing the tourism destination brand image and its impact on the behavior of internal tourists (case study: the city of Qazvin). Tourism Studies, 3(2), 138-122.

4. Jomeini, Davoud and Jamshidi, Alireza (2011). Identify and prioritize the factors affecting the level of satisfaction of tourists (Case Study: Border marketplace city Javanrood). Tourism Studies, 2, 200-181.

5. Juandi V.S., Andari R., and Setiyorini H.P.D. (2018). The Influence of Sustainable Tourism Development towards Tourists' Satisfaction in Saung Angklung Udjo. IOP Conf. Series: Earth and Environmental Science, 145.

6. Rahnama, Mohammad Rahim and Hoseini Ghafari, Tahereh Sadat and Ashnouie, Amir, Rousta, Mojtaba (2012). Tourism Studies, 2, 89-68.

7. Rahnamaei, Mohammad Taghi and Farhoudi, Rahmatoallah and Ditman, Anderias and Ghadami, Mostafa (2008). Study of the area of tourist destination capacity with an emphasis on host community (Case study: the city of Kalardasht). The Study Of Human Geography, 66, 17-33.

8. Soltani, Sahar and Shahnoushi, Naser (2011). Prioritizing the major tourist attractions in the city of Mashhad in terms of domestic tourism. Tourism Studies, 1, 5-17.

9. Seifodini, Faranak and Shourjeh, Mahmoud (2011). Stretching capacity modeling and management of monuments in tourist areas (Case Study Temple City Kangavar). Tourism Studies. 15(7), 137-177.

10. Shaabanifard, Mohammad and Pourahmad, Ahmad and Hoseini, Ali and Rashidi, Mostafa (2009). Investigate the capacity of urban tourism and sustainable tourism cities modeling based on physical dimension (Case study: 12'Th area of Tehran). Journal of Geographical Sciences and Applied Research, 14(11), 47-74.

11. Firouzabad,and Anad Imani Jajromi, H (2012). The villagers satisfaction and related factors village-aid functions (Case study: the villages of Qazvin). Rural Research, 3(1), 91-61.

12. Gadami, Mostafa (2011). Assessment and strategy codificationwithin the context of sustainable development of tourism destinations, case study: Mashhad metropolitan. Urban And Regional Studies, 3(9), 82-59.

13. Nourollahifarakhili, Mahmoud (2004). The impact of religious tourists on the physical transformation of the old areas of city of Mashhad. MS Thesis, University martyr Beheshti.

14. Noghani, Mohsen and Ghahrman, Arash and Effati, Sommaieh (2012). Factors influencing the satisfaction of tourists traveling to Mashhad (Case Study: the family foundation of martyr), Tourism Studies, 1(2), 116-136.

15. Chi, G. (2005). A study of developing destination loyalty model. Doctoral Dissertation, Oklahoma State University.

16. Choi, S. Hwan (2003). Measurement of Sustainable Development progress for Managing Community Tourism, Dissertation for PHD, Texas A\&M University.

17. Huang, R., \& Sarigöllü, E. (2008). Assessing satisfaction with core and secondary attributes. Journal of Business Research, 61(9), 942-949.

18. Inskeep, E. (2015). National and regional tourism planning: methodologies and case studies. London: Rutledge. 
19. Saberifar, R., Shokri, H., \& Mohamadnejad, M. (2015). Urban sustainable development. Mashhad, Omid Meher.

20. Statistics of Mashhad (2018). Deputy of planning and development of Municipality, Mashhad.

21. Truong, T. H., \& Foster, D. (2006). Using HOLSAT to evaluate tourist satisfaction at destinations: The case of Australian holidaymakers in Vietnam. Tourism Management, 27, 842-855.

22. Wong, J., \& Law, R. (2003). Difference in Shopping Satisfaction Levels: A Study of Tourists in Hong Kong. Tourism Management, 24, 401-410. 